\title{
Interactive comment on "Freeze-thaw processes of active layer regulate soil respiration of alpine meadow in the permafrost region of the Qinghai-Tibet Plateau” by Junfeng Wang et al.
}

Junfeng Wang et al.

wangjf2008@Izb.ac.cn

Received and published: 30 December 2019

We are grateful to anonymous reviewers for their helpful and constructive suggestions and comments. We have tried our best to address all issues raised by them, which we believe improve the manuscript substantially. The revised contents and detailed responses to the valuable questions are attached as supplement.

Please also note the supplement to this comment:

https://www.the-cryosphere-discuss.net/tc-2019-214/tc-2019-214-AC2supplement.pdf 
Interactive comment on The Cryosphere Discuss., https://doi.org/10.5194/tc-2019-214, 2019.

Interactive

comment 